\title{
Research on application of high performance alkali-free liquid accelerator in shotcrete support
}

\author{
Luchen Zhang ${ }^{1, *}$, Xuena $\mathrm{Jia}^{1}$, Guanjie Yang ${ }^{2}$, and Chaoqun Sun ${ }^{1}$ \\ ${ }^{1}$ School of Transportation and Civil Engineering, Shandong Jiaotong University, Jinan, Shandong 250357, China \\ ${ }^{2}$ The second construction limited company of china construction eighth engineering division, Jinan, Shandong 250001, China
}

\begin{abstract}
At present, sprayed concrete has problems such as low strength, large rebound amount, and high dust concentration. Developed a new type of alkali-free liquid accelerator, which can effectively improve the performance of shotcrete. The alkali-free liquid accelerator is mainly composed of aluminum sulfate, active aluminum hydroxide, alcohol amine, amide, and stabilizer. Through laboratory tests and field tests, when the alkali-free liquid accelerator admixture is $5 \%$ to $7 \%$, the initial setting time is within 5 minutes, and the final setting time is within 10 minutes. The strength of shotcrete reaches $12.8 \mathrm{MPa}$ in one day, and the compressive strength ratio of $28 \mathrm{~d}$ is more than $95.3 \%$, and the rebound amount is within $10 \%$. Compared with ordinary alkali-free liquid accelerator and alkaline liquid accelerator, the strength of sprayed concrete mixed with the alkali-free liquid accelerator is greatly improved, which is more conducive to the support of the sprayed layer, reduced rebound and dust, effectively improve the construction environment and increase construction efficiency.
\end{abstract}

\section{Introduction}

Sprayed concrete is widely used in various types of surrounding rock support such as tunnels, subways and mines. It forms an initial support together with anchor rods, steel mesh, steel grids and steel arches to play a role in stabilizing the rock mass. Accelerator is the most important admixture in sprayed concrete, which makes the concrete harden quickly, reduce rebound, increase the thickness of one shot, and improve early strength[12]. There are mainly two types of accelerators, namely powder accelerators and liquid accelerators. With the improvement of engineering quality and environmental protection requirements, the application of liquid accelerators is becoming more and more widespread.

The first generation of accelerator was jointly produced by Austria and Switzerland. Its main component is sodium silicate, which has a history of nearly 100 years. Since 1960, a series of accelerators have appeared. The main components are aluminates and carbonates. These accelerators are powdery accelerators with high alkali content. The early powdery accelerator in China was mainly composed of alumina clinker, lime and carbonate in a certain proportion. When the content was $3 \%$, the initial setting time was within 2 minutes, the final setting time was within 5 minutes, and the subsequent strength loss was $30 \%$ the above. The development of liquid accelerators began in the late 1970s, sodium aluminate and sodium carbonate high alkaline liquid accelerators were first developed by Japan and the United States on the basis of powdery accelerators. In the 1980s, started the development of low-alkali and alkali-free liquid accelerators and gradually became a development trend[3-4].

The powdery accelerator is mainly used in dry-mix sprayed concrete. Because the water in the dry sprayed concrete is added at the sprinkler head and the amount of water is uncontrollable, it results in a large amount of rebound, high dust concentration, low strength and large dispersion in the sprayed concrete during construction. Liquid accelerators are mainly used in wet-mix sprayed concrete. Compared with dry-mix sprayed concrete, they have higher strength, lower rebound and dust. Liquid accelerators are divided into alkaline and alkali-free ones. Alkaline liquid accelerators can easily induce the alkaliaggregate reaction of concrete, resulting in a large loss of strength in the later stage. Alkali-free liquid accelerators do not have this phenomenon and have been widely used.

At present, alkali-free liquid accelerators have problems such as poor stability, large amounts, and toxic substances. The main quick-setting components of alkali-free accelerators at home and abroad are aluminum sulfate, and aluminum ions are prone to hydrolysis-aggregation in water. The solubility of aluminum salt is very small, and there are few effective ingredients. Crystallization and precipitation will occur when the accelerator is left for a long time. Existing alkali-free liquid accelerators are generally added in an amount of $8 \%$ to $10 \%$, and the amount is too large, which greatly increases the construction cost and is easy to collapse during the spraying process. Adding fluoride to some accelerators, fluoride ions can shorten the setting time of cement and play a role in accelerating the setting, but fluoride is generally toxic[5-7]. In view of

Corresponding author: 2473038977@qq.com 
this, a new type of alkali-free liquid accelerator has been developed, which has the characteristics of small dosage, strong adaptability, good stability and non-toxicity, and relevant laboratory and field tests have been conducted to study its performance, provide theoretical basis and data support for the promotion and application of materials.

\section{Development of alkali-free liquid accelerator}

The main component of ordinary alkali-free liquid accelerators is aluminum sulfate solution, with a solid content of $30 \%$ to $40 \%$, which results in a higher content of alkali-free liquid accelerators. Based on the coagulation promoting mechanism of the alkali-free liquid quick-setting agent, the content of the active ingredient aluminum ion in the solution is increased, and amorphous aluminum hydroxide powder is added to the solution. The main constituents of the alkali-free liquid accelerator were finally determined: aluminum sulfate, active aluminum hydroxide, triethanolamine, polyacrylamide, and stabilizers, among which aluminum sulfate and aluminum hydroxide were the main quicksetting components.

Aluminum sulfate is selected from polyaluminum sulfate. The content of $\mathrm{Al}_{2} \mathrm{O}_{3}$ is greater than $18 \%$. The content of ordinary industrial-grade $\mathrm{Al}_{2} \mathrm{O}_{3}$ is generally $14 \% \sim 16 \%$, and the mass fraction in solution is $40 \% \sim 60 \%$. The addition of aluminum hydroxide is to increase the content of the active ingredient aluminum ion in the solution. The powdery amorphous active aluminum hydroxide is selected. It has better solubility than the crystalline aluminum hydroxide, and its mass fraction in the solution is $5 \% \sim 25 \%$. Triethanolamine is an early strength agent, which can shorten the early setting time of cement hydration, and can form complex ions that are easily soluble in water with aluminum ions, reduce the polymerization precipitation of aluminum ions, and act as a stabilizer. Polyacrylamide is a thickener that improves the cohesiveness of the solution and helps reduce the rebound of sprayed concrete. The role of the stabilizer is mainly to maximize the dissolution of aluminum sulfate and aluminum hydroxide, and prevent aluminum sulfate crystallization and aluminum ion hydrolysis sedimentation, increase the concentration of aluminum ions in the solution, thereby increasing the content of active ingredients and reducing the dosage of accelerator.

The mass percentage of each component in the solution is: $40 \% \sim 50 \%$ of polyaluminum sulfate, $5 \%$ $\sim 20 \%$ of active aluminum hydroxide, $0.5 \% \sim 2 \%$ of alcohol amine, $0.5 \% \sim 2 \%$ of amide, and $1 \% \sim 3 \%$ of stabilizer. The formulated alkali-free liquid coagulant has a solid content of more than $60 \%$, and no precipitation or crystallization occurs. The reaction temperature is $70 \sim 90{ }^{\circ} \mathrm{C}$, and the reaction time is $2 \sim 3 \mathrm{~h}$. Figure 1 shows the preparation process of the alkali-free liquid accelerator.

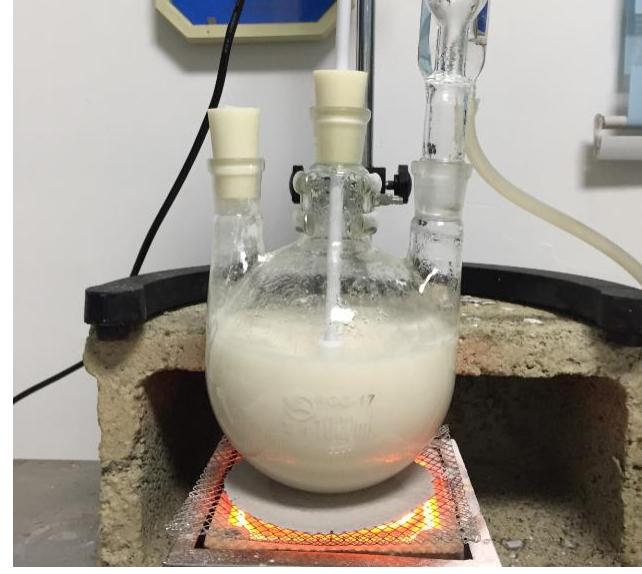

Fig. 1. Preparation of alkali-free liquid accelerator

\section{Material performance test}

The test materials used benchmark cement, standard sand, homemade alkali-free liquid accelerator, ordinary alkali-free liquid accelerator and alkaline liquid accelerator. The laboratory test method adopts the requirements in the "Accelerator for shotcrete" (GB/T 35159-2017) standard, and measures the initial and final setting time of cement paste and the strength of cement mortar. Carry out shotcreting test on site, and measure rebound amount, strength and other indexes.

\subsection{Test method}

(1) Determination of setting time of cement paste: Weigh $400 \mathrm{~g}$ cement, water $140 \mathrm{~g}$ (deducting water content in liquid accelerator). Pour the cement and water into the cement paste mixer for mixing, stop mixing at low speed for $30 \mathrm{~s}$, add liquid accelerator with syringe, mix at low speed for $5 \mathrm{~s}$, and then quickly mix for $15 \mathrm{~s}$. After mixing, immediately put into the mold, gently vibrate and scrape the surface. From the addition of accelerator, the whole process is controlled within 50s. The setting time was measured by Vicat Apparatus every 10 seconds until the initial setting and final setting.

(2) Determination of strength of cement mortar: Weigh $900 \mathrm{~g}$ cement, $1350 \mathrm{~g}$ standard sand, water cement ratio is 0.5 , mix the mortar evenly, add liquid accelerator, stir for $5 \mathrm{~s}$ at low speed, and then quickly stir for $15 \mathrm{~s}$. From adding accelerator, the whole process is controlled within 50s. The mortar was made into $40 \mathrm{~mm} \times 40 \mathrm{~mm}$ $\times 160 \mathrm{~mm}$ test block, and cured in the standard curing room with temperature of $20{ }^{\circ} \mathrm{C} \pm 2{ }^{\circ} \mathrm{C}$ and humidity of more than $95 \%$. The strength of $1 \mathrm{~d}$ and $28 \mathrm{~d}$ was measured and the strength ratio was calculated.

Performance requirements of paste and mortar mixed with accelerator are shown in Table 1.

Table 1. Properties of paste and mortar mixed with accelerator

\begin{tabular}{|l|c|c|c|}
\hline \multicolumn{2}{|c|}{ item } & $\begin{array}{c}\text { Alkali-free } \\
\text { accelerator }\end{array}$ & $\begin{array}{c}\text { Alkali } \\
\text { accelerator }\end{array}$ \\
\hline $\begin{array}{l}\text { Setting } \\
\text { time of }\end{array}$ & $\begin{array}{c}\text { Initial setting } \\
\text { time } / \mathrm{min}\end{array}$ & \multicolumn{2}{|c|}{$\leqslant 5$} \\
\hline
\end{tabular}




\begin{tabular}{|c|c|c|c|}
\hline paste & $\begin{array}{l}\text { Final setting time } \\
\text { /min }\end{array}$ & \multicolumn{2}{|c|}{$\leqslant 12$} \\
\hline \multirow{2}{*}{$\begin{array}{l}\text { Mortar } \\
\text { strength }\end{array}$} & $\begin{array}{l}\text { 1d compressive } \\
\text { strength/MPa }\end{array}$ & \multicolumn{2}{|c|}{$\geqslant 7.0$} \\
\hline & $\begin{array}{l}\text { 28d compressive } \\
\text { strength ratio / } \%\end{array}$ & $\geqslant 90$ & $\geqslant 70$ \\
\hline
\end{tabular}

\subsection{Laboratory test- Setting time}

For self-made alkali-free liquid accelerator, ordinary alkali-free liquid accelerator and alkaline liquid accelerator, the setting time of cement paste was measured. The amount of homemade alkali-free liquid accelerator was $4 \% \sim 8 \%$. The amount of ordinary alkalifree liquid accelerator is $6 \% \sim 10 \%$, and the amount of alkali liquid accelerator is $3 \% \sim 7 \%$. The initial and final setting time are shown in Figures 2, 3 and 4, respectively.

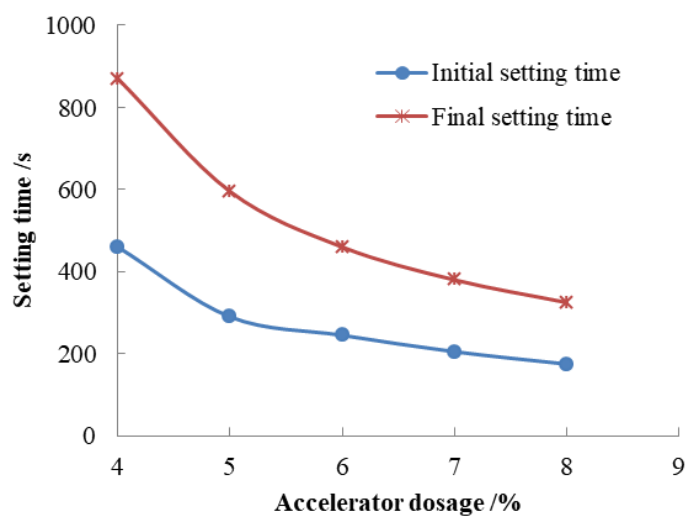

Fig. 2. Self-made alkali-free liquid accelerator

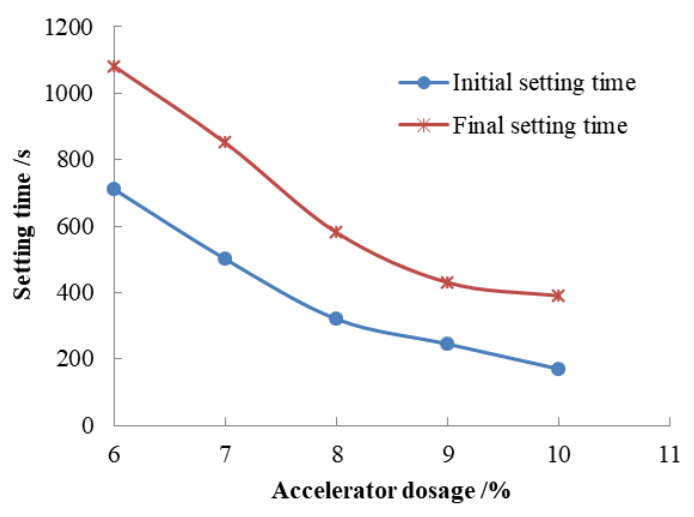

Fig. 3. Ordinary alkali-free liquid accelerator

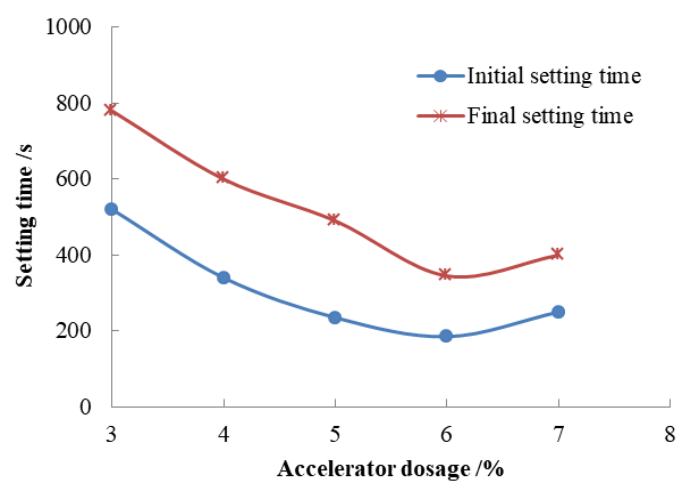

Fig. 4. Alkaline liquid accelerator
As shown in Figure 2, when the dosage of self-made alkali-free liquid accelerator is $4 \% \sim 8 \%$, the coagulation effect is better as the amount is increased. The dosage is more than 5\%, which meets the standard requirements. As shown in Figure 3, when the amount of ordinary alkali-free liquid accelerator is $6 \% \sim 10 \%$, as the amount increases, the better the coagulation effect, the more the amount is $8 \%$ or $9 \%$ to meet requirements in the standard. As shown in Figure 4, the alkaline liquid accelerator is not the better the effect with the increase of the amount, but there is an optimal mixing amount. The optimal amount of the alkaline liquid setting agent selected in this paper is $6 \%$. When the content is more than $5 \%$, it can meet the requirements of the standard. Therefore, it can be seen that even when the amount of the alkaline liquid accelerator is low, the coagulation effect is still good. The self-made alkali-free liquid accelerator has better coagulation effect than ordinary alkali-free liquid accelerator.

\subsection{Laboratory test-Mortar strength}

Cement mortar strength tests were performed on three liquid accelerators. The test results are shown in Table 2 .

Table 2. Strength and strength ratio of cement mortar mixed with accelerator

\begin{tabular}{|c|c|c|c|}
\hline \multirow{2}{*}{$\begin{array}{c}\text { Accelerator } \\
\text { type }\end{array}$} & $\begin{array}{c}\text { Accelerator } \\
\text { dosage /\% }\end{array}$ & $\begin{array}{c}\text { 1d } \\
\text { compressive } \\
\text { strength } \\
\text { /MPa }\end{array}$ & $\begin{array}{c}\text { 28d } \\
\text { compressive } \\
\text { strength } \\
\text { ratio }\end{array}$ \\
\hline \multirow{2}{*}{$\begin{array}{c}\text { Blank } \\
\text { sample }\end{array}$} & 0.0 & 9.2 & 100 \\
\hline \multirow{4}{*}{$\begin{array}{c}\text { Alkaline } \\
\text { liquid }\end{array}$} & 3.0 & 9.6 & 96.4 \\
\cline { 2 - 4 } accelerator & 4.0 & 10.4 & 91.5 \\
\cline { 2 - 4 } & 5.0 & 11.5 & 85.3 \\
\cline { 2 - 4 } & 6.0 & 12.6 & 81.2 \\
\hline \multirow{4}{*}{$\begin{array}{c}\text { Ordinary } \\
\text { alkali-free } \\
\text { liquid }\end{array}$} & 7.0 & 12.1 & 74.6 \\
\cline { 2 - 4 } accelerator & 7.0 & 9.8 & 98.5 \\
\cline { 2 - 4 } & 9.0 & 11.9 & 95.2 \\
\cline { 2 - 4 } & 10.0 & 12.5 & 89.5 \\
\hline \multirow{4}{*}{$\begin{array}{c}\text { Self-made } \\
\text { alkali-free } \\
\text { liquid }\end{array}$} & 4.0 & 12.8 & 82.8 \\
\cline { 2 - 4 } accelerator & 5.0 & 11.4 & 98.6 \\
\cline { 2 - 4 } & 6.0 & 12.8 & 96.2 \\
\cline { 2 - 4 } & 7.0 & 13.5 & 95.3 \\
\hline \multirow{2}{*}{\begin{tabular}{c} 
any \\
\cline { 2 - 4 }
\end{tabular}} & 13.2 & 96.7 \\
\hline
\end{tabular}

It can be known from Table 2 that the three liquid accelerators can increase the $1 \mathrm{~d}$ strength of the mortar in the test admixture range. With the increase of the amount of alkaline liquid accelerator, the $28 \mathrm{~d}$ strength ratio of cement mortar is smaller. When the content is $7 \%$, the mortar strength ratio is only $74.6 \%$. In the test range of alkali-free liquid accelerator, the intensity ratio of $28 \mathrm{~d}$ can be guaranteed to be more than $90 \%$, and the strength ratio has no obvious change trend with the increase of 
the dosage. Compared with the ordinary alkali-free accelerator, the self-made alkali-free liquid accelerator has a higher strength ratio at 28 days.

\subsection{Field test}

The self-made alkali-free liquid accelerator was tested in the field. C25 shotcrete was used on site, and the mix proportion was cement: Sand: Gravel: water reducer: water $=460 \mathrm{Kg}: 930 \mathrm{~kg}: 920 \mathrm{~kg}: 4.6 \mathrm{~kg}: 207 \mathrm{~kg}$. The selfmade alkali-free liquid accelerator was used with the dosage of $5 \%$. The field spray plate test was carried out, and the strength was compared with that of adding alkaline liquid accelerator, the dosage is $7 \%$. After curing, the standard test block of $150 \mathrm{~mm} \times 150 \mathrm{~mm} \times$ $150 \mathrm{~mm}$ was cut and the strength of $1 \mathrm{~d}, 7 \mathrm{~d}$ and $28 \mathrm{~d}$ was measured. The test data are shown in Table 3.

Table 3. Determination of the strength of shotcrete

\begin{tabular}{|c|c|c|c|c|c|}
\hline \multirow{2}{*}{$\begin{array}{l}\text { Sample } \\
\text { number }\end{array}$} & \multirow{2}{*}{$\begin{array}{l}\text { Age } \\
/ \mathrm{d}\end{array}$} & \multicolumn{2}{|c|}{$\begin{array}{l}\text { Adding alkaline } \\
\text { accelerator / } \mathrm{MPa}\end{array}$} & \multicolumn{2}{|c|}{$\begin{array}{c}\text { Adding self- } \\
\text { made alkali-free } \\
\text { accelerator } / \mathrm{MPa}\end{array}$} \\
\hline & & $\begin{array}{l}\text { block } \\
\text { value }\end{array}$ & $\begin{array}{l}\text { mean } \\
\text { value }\end{array}$ & $\begin{array}{l}\text { block } \\
\text { value }\end{array}$ & $\begin{array}{l}\text { mean } \\
\text { value }\end{array}$ \\
\hline 1 & \multirow{3}{*}{1} & 10.7 & \multirow{3}{*}{11.3} & 13.3 & \multirow{3}{*}{12.8} \\
\hline 2 & & 11.8 & & 11.9 & \\
\hline 3 & & 11.4 & & 13.2 & \\
\hline 1 & \multirow{3}{*}{7} & 17.2 & \multirow{3}{*}{18.2} & 24.3 & \multirow{3}{*}{23.9} \\
\hline 2 & & 18.3 & & 23.6 & \\
\hline 3 & & 19.1 & & 23.8 & \\
\hline 1 & \multirow{3}{*}{28} & 28.4 & \multirow{3}{*}{27.4} & 29.4 & \multirow{3}{*}{31.3} \\
\hline 2 & & 27.6 & & 31.9 & \\
\hline 3 & & 26.2 & & 32.6 & \\
\hline
\end{tabular}

It can be seen from Table 3 that the $28 \mathrm{~d}$ strength of the sprayed concrete using alkaline liquid accelerator is $27.4 \mathrm{MPa}$, and the $28 \mathrm{~d}$ strength of the self-made alkalifree liquid accelerator is $31.3 \mathrm{MPa}$, which increases the strength by $14 \%$. It can also be seen from the table that the strength of the shotcrete $1 \mathrm{~d}$ is higher than that of the alkaline liquid accelerator, indicating that the self-made alkali-free liquid accelerator can also quickly increase the early strength of the shotcrete.

In the process of on-site spraying, adding the selfmade alkali-free liquid accelerator has good working performance and no collapse. The measured rebound can be controlled within $10 \%$. Field test photos are shown in Figure 5.

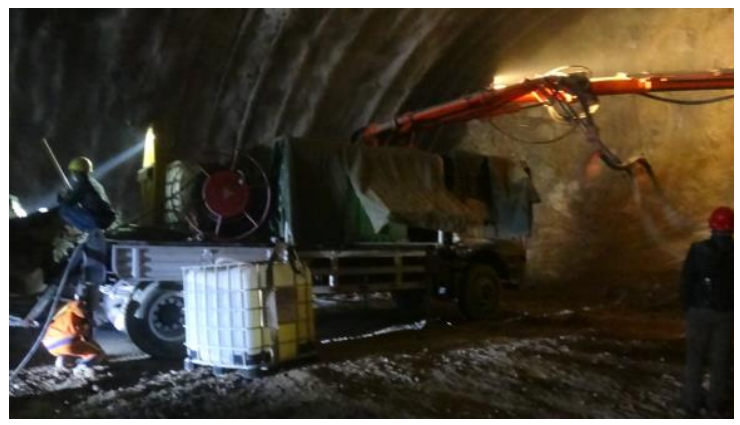

Fig. 5. Field test photos

\section{Conclusion}

(1) When the amount of self-made alkali-free liquid accelerator is $5 \%$, the initial setting time was $4 \mathrm{~min} 50 \mathrm{~s}$, the final setting time was 9 min $55 \mathrm{~s}$, and the $28 \mathrm{~d}$ mortar strength ratio was $98.6 \%$, all meeting the requirements in the standard.

(2) With the increase of the amount of alkali-free liquid accelerator, the quick-setting effect is better. As the amount of alkaline liquid accelerator increases, the quick-setting effect becomes better and worse, which means for the best dosage, pay attention to controlling the dosage of accelerator in construction.

(3) Due to the high content of active ingredients, the self-made alkali-free liquid accelerator has a small dosage. The small dosage is conducive to the construction of sprayed concrete, reducing collapse and reducing rebound. At the same time, the alkali-free liquid accelerator can ensure the strength of the sprayed concrete and is beneficial to the stability of the surrounding rock of the tunnel.

\section{References}

1. Baoshu G. Technique of shotcrete support for tunnel and underground works. China Communications Press(2009)

2. Liangkui C. Shotcrete. China Architecture and Building Press(1990)

3. Junpeng R, Benxiu L, Yu W, et al. Research on preparation and properties of new liquid non-alkali liquid accelerator for shotcrete. Journal of Shandong Chemical Industry, 48, 3-6(2019)

4. Guangbing Z. Progress of the research for shotcrete. Journal of Concrete, 258, 105-109(2011)

5. Jong Pil W, Un Jong H, Cheol Keun K, Su Jin L. Mechanical performance of shotcrete made with a high-strength cement-based mineral accelerator. Journal of Construction and Building Materials, 49, 175-183(2013)

6. Xiongfei H, Xun Z. Study on acceleration mechanism of liquid alkali-free accelerating components. Journal of Tunnel construction, 34, 1131-1136(2014)

7. Jingyu M, Zhongcheng $M$, Lan $W$, et al. Performance and mechanism of a new alkali-free and chloride-free liquid accelerator. Journal of Wuhan University of Technology, 34,14-18(2012) 